\title{
MESSAGE FROM THE CHAIRMAN OF THE SCIENTIFIC COMMITTEE
}

In recent years, Healthcare industry has been undergoing major transformation and concepts revolving around quality, safety and value-based care are becoming the core of discussion in most scientific platforms.

At a regional level, MNGHA and KSAU-HS started preaching for healthcare quality \& safety and patient empowerment via the swiftly growing Patient Safety Forum that soon became the most regionally prominent platform and internationally recognized scientific forum addressing quality and patient safety.

A robust program comprising significant keynotes, plenary sessions and well-structured workshops have been quite appealing to attract local, regional and international experts and healthcare providers.

This year where the 9th Patient Safety Forum is being hosted in Jeddah, I would like to extend my gratitude to the leadership of MNGHA \& KSAUHS for the tireless support for this important forum to successfully continue serving its purpose.

Thanks and appreciation to Scientific and Organizing Committee members for their great efforts in orchestrating such a wonderful program

My warm and heartfelt welcome to all speakers, participants and attendees.

\section{Dr. Mohammed Alzahrani}

Executive Director,

Medical Services-WR Chair, Scientific Committee

Ministry of National Guard Health Affairs 